\title{
MICROLEARNING AS A TOOL FOR SCIENTIFIC DISSEMINATION: THERMAL ANALYSIS OF THE PORTUGUESE GOOD LUCK ROOSTER
}

\author{
Raquel Magri ${ }^{\mathrm{a}}$, Caroline Gaglieri ${ }^{\mathrm{a}}$, Rafael Turra Alarcon ${ }^{\mathrm{a}}$, Aguinaldo Robinson de Souza ${ }^{\mathrm{a}}$ and Gilbert Bannach $^{\mathrm{a}, *,(1)}$ \\ a'Departamento de Química, Faculdade de Ciências, Universidade Estadual Paulista, 17033-260 Bauru - SP, Brasil
}

Recebido em 30/06/2021; aceito em 05/10/2021; publicado na web em 10/11/2021

\begin{abstract}
This work aims to produce and disseminate videos that follow the microlearning methodology, to explain the physicochemical properties of cobalt (II) chloride hexahydrate through thermal analysis, and to determine the reliability of the Portuguese good luck rooster. Temporal and social accelerations due to the growth of the technological world are changing the old teaching-learning methodologies; thus, new methods should be explored. In the microlearning methodology, short segments and specific content can be broadcast to anyone at any time. In addition, relating new information to individual's experiences can favor the teaching-learning process. The good luck rooster is an ornament of Portuguese origin, which can forecast the weather in a limited way, and is composed of cobalt (II) chloride hexahydrate. This compound was characterized by TG-DTA (Simultaneous Thermogravimetry-Differential Thermal Analysis) and DSC (Differential Scanning Calorimetry), verifying that the salt loses its hydration water when exposed to high temperatures, changing its color from pink color to blue.
\end{abstract}

Keywords: cobalt (II) chloride hexahydrate; microlearning; Thermal Analysis.

\section{INTRODUCTION}

In recent years, the use of technologies has grown exponentially, especially after the Covid-19 pandemic, and accelerated of the pace of life, forming an immediate society. Educational institutions have had to keep up with this pace, seeking new teaching strategies and methodologies aimed at the continuity and quality of the teaching and learning process..$^{1-3}$ Non-formal education, which is intentional but minimally structured and systematized, has gained visibility, especially in the media. ${ }^{4}$

This scenario encompasses microlearning methodologies, approaching content in a reduced way, distributing knowledge in small and understandable fractions, interconnecting short learning activities, and focusing on individual learning needs. In this method, the speed of learning is self-determined, because access to the content can be done at the time and pace they want. In addition, recent studies show that this teaching methodology can improve learning capacity compared to the traditional method, by facilitating the retention of information effectively and helping long-term memory. In this context, the concepts of microlearning and micro-knowledge offer flexible and dynamic alternatives that are necessary due to imposed media and social changes..$^{5-7}$

One way of introducing new information to someone is to start from a problem related to the individual's context, for two reasons: first, contextualization facilitates understanding; the second reason is related to whether that information will be meaningful or not to the subject, as the person only learns out of necessity, and not simply for learning. Therefore, learning will be meaningful if it can be applied to lived experiences. ${ }^{8,9}$

The good luck rooster is a decorative object of Portuguese origin, that changes its color according to changes in weather. The rooster is coated with an absorbent material and has its body impregnated with cobalt (II) chloride hexahydrate. If the weather is dry (with no chance of rain), the cobalt chloride loses water molecules and turns to a blue color. When the relative humidity of the air is high, the cobalt chloride hydrates, turning pink. In addition, temperature

*e-mail: gilbert.bannach@unesp.br variations influence the color change: at high temperatures, the rooster turns blue; at low temperatures, it turns pink. Consequently, the pink color of the rooster's body indicates the possibility of rain with mild temperatures. In Brazil, this object is known as the 'Galo do tempo' ${ }^{10}$

This work employs thermal characterization of the cobalt (II) chloride hexahydrate, present in the Portuguese good luck rooster, to explain the physicochemical characteristics and to determine the reliability of this adornment. In addition, videos were produce following the methodology of microlearning as a tool for scientific dissemination of thermoanalytical results.

\section{EXPERIMENTAL}

\section{Thermal Analysis}

Simultaneous Thermogravimetry-Differential Thermal Analysis (TG-DTA)

Simultaneous TG-DTA curves were obtained in a STA 499 F3 equipment (Netzsch), using open $200 \mu \mathrm{L} \alpha$-alumina crucibles and a $15 \mathrm{mg}$ of cobalt (II) chloride hexahydrate (ACS, Sigma-Aldrich, 98\%) and was used without further purification or thermal treatment. The equipment was adjusted to a heating rate of $10^{\circ} \mathrm{C} \mathrm{min}^{-1}$, using a dry air flow of $70 \mathrm{~mL} \mathrm{~min}-1$. The temperature range was from $30^{\circ} \mathrm{C}$ to $1000{ }^{\circ} \mathrm{C}$.

\section{Differential Scanning Calorimetry (DSC)}

Mettler-Toledo DSC1 Stare equipment was used for DSC curves, and $10 \mathrm{mg}$ of cobalt (II) chloride hexahydrate were inserted into an aluminum crucible $(40 \mu \mathrm{L})$. The equipment was adjusted to a heating rate of $10{ }^{\circ} \mathrm{C} \mathrm{min}^{-1}$ in dry air atmosphere with a flow of $50 \mathrm{~mL} \mathrm{~min}{ }^{-1}$. The analyzes were performed in the range of 25 to $250{ }^{\circ} \mathrm{C}$.

\section{Video Production}

Dehydration of cobalt (II) chloride hexahydrate - microanalysis

The images of cobalt (II) chloride hexahydrate were obtained during DSC analysis, with a SC30 Olympus digital camera with 3.3 megapixels CMOS sensor, and a Navitar 1-6232D 6.5x 
magnification with $3 \mathrm{~mm}$ fine focus and detents, photographed every $0.6{ }^{\circ} \mathrm{C}$. The conditions used were the same cited in DSC analysis, excepted by the crucible, which was $\alpha$-alumina ( $40 \mathrm{uL}$ ). AnalySIS Docu 5.2(Build 3554) was used to join the images and produce a video.

\section{Microlearning}

Wondershare Filmora, version 10.2.0.32(6.6.1.34) was used to record and to edit the "Glycerol Thermal Analysis" and "Is portuguese good luck rooster trustworthy?" videos.

\section{RESULTS AND DISCUSSIONS}

\section{Thermal Analysis}

\section{Simultaneous Thermogravimetry-Differential Thermal Analysis (TG-DTA)}

Figure 1 exhibits the TG/DTG-DTA curves of cobalt (II) chloride hexahydrate $\left(\mathrm{CoCl}_{2} \cdot 6 \mathrm{H}_{2} \mathrm{O}\right)$. The first derivative of the TG curve (DTG) was used to assist intervals of mass loss observed in the TG curves. The compound is stable up to $31.2{ }^{\circ} \mathrm{C}$. In addition, the DTG curve indicates three consecutive and complex mass losses $\left(\Delta m_{\text {exp }}=45.2 \%\right)$. They overlap between 31.2 and $202.5^{\circ} \mathrm{C}$, which is related to the loss of hydration water and can be confirmed by four endothermic peaks in the DTA curve. Stoichiometry elucidated that the compound lost its six water molecules since they represent $45.4 \%$ of the total mass $\left(\Delta m_{\text {exp }}=45.2 \%\right)$.

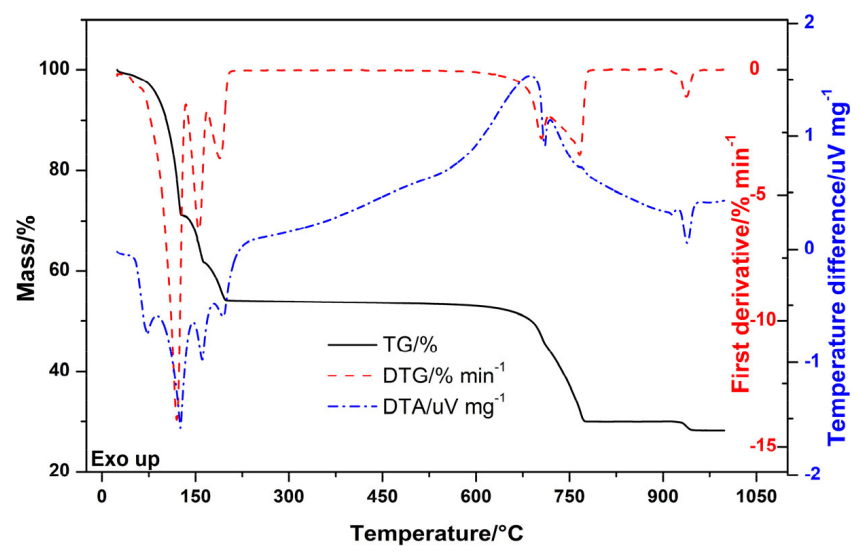

Figure 1. TG/DTG-DTA curves for $\mathrm{CoCl}_{2} \cdot 6 \mathrm{H}_{2} \mathrm{O}$

By DTG, the mass loss between 31.2 and $128.5^{\circ} \mathrm{C}\left(\Delta m_{\exp }=28.1 \%\right)$ is related to the endothermic peaks in the DTA curve at $71.5^{\circ} \mathrm{C}$ and $120.3{ }^{\circ} \mathrm{C}$. The first is related to the loss of two water molecules that make hydrogen bonds and are coordinated outside the coordination sphere $\left[\mathrm{CoCl}_{2}\left(\mathrm{OH}_{2}\right)_{4}\right] \cdot 2 \mathrm{H}_{2} \mathrm{O}$, and after the water loss, it becomes $\left[\mathrm{CoCl}_{2}\left(\mathrm{OH}_{2}\right)_{4}\right]$. The second event refers to the loss of two water molecules of crystallization. These two events are simultaneous and therefore occur in just one step, forming a blue acid complex (Figure 2). ${ }^{11,12}$ In addition, X-Ray structure analysis determined that above $50{ }^{\circ} \mathrm{C}$ there is no evidence of the hexahydrate salt. ${ }^{13}$ The peak at $158.7^{\circ} \mathrm{C}$ is due to the loss of structural water, covalently bound to the metal, and the peak at $189.5^{\circ} \mathrm{C}$ occurs by the loss of coordination water, forming the anhydro $\mathrm{CoCl}_{2} \cdot{ }^{11,12}$

Furthermore, DTG enabled observation of two more mass losses $\left(\Delta m_{\text {exp }}=20.7 \%\right)$, consecutive and complex, between 605.9 and $759.8{ }^{\circ} \mathrm{C}$, related to the endothermic peak at $711.8{ }^{\circ} \mathrm{C}$ due to the decomposition of the compound releasing chlorine and its transformation into cobalt (II,III) oxide $\left(\mathrm{Co}_{3} \mathrm{O}_{4}\right)$. Finally, the last step of mass loss $\left(\Delta m_{\text {exp }}=1.9 \%\right)$ occurs between 903.5 and $946.0^{\circ} \mathrm{C}$, presenting the endothermic event at $922.1^{\circ} \mathrm{C}$ due to the formation of cobalt (II) oxide ( $\mathrm{CoO})$, in agreement with literature, obtaining a dark gray powder as residue $(\Delta m=31.3 \%) .^{14,15}$ The temperatures related to the TG/DTG-DTA curves can be seen in Table 1 .

Table 1. Thermal Events $(\theta)$, Loss of experimental mass $\left(\Delta m_{\text {exp }}\right)$, loss of theorical mass $\left(\Delta m_{\text {calc }}\right)$, residual mass $\left(\Delta m_{\text {res }}\right)$, and Peak Temperature $(T p)$ observed in TG-DTA curve for $\mathrm{CoCl}_{2} \cdot 6 \mathrm{H}_{2} \mathrm{O}$

\begin{tabular}{lcccc}
\hline & $1^{\text {st }}$ step & $2^{\text {nd }}$ step & $3^{\text {rd }}$ step & residue/ $\%$ \\
\hline$\theta /{ }^{\circ} \mathrm{C}$ & $31.2-202.5$ & $605.9-759.8$ & $903.5-946.0$ & \\
$\Delta m_{\text {exp }} / \%$ & 45.2 & 21.7 & 1.9 & 31.3 \\
$\Delta m_{\text {calc }} / \%$ & 45.4 & 20.9 & 2.2 & 31.5 \\
$T p /{ }^{\circ} \mathrm{C}$ & $\downarrow 71.5, \downarrow 120.3$, & $\downarrow 711.8$ & $\downarrow 922.1$ & \\
& $\downarrow 158.7, \downarrow 189.5$ & & & \\
\hline
\end{tabular}

$\downarrow$ Endothermic peak.

\section{Differential Scanning Calorimetry (DSC)}

The DSC curve (Figure 3) confirms the events presented in the DTA curve. The endothermic peaks at $68.6{ }^{\circ} \mathrm{C}$ and $101.9{ }^{\circ} \mathrm{C}$ $\left(\Delta H=691.6 \mathrm{~J} \mathrm{~g} \mathrm{~g}^{-1}\right)$ are related to the loss of two surface water molecules and two structural ones, respectively, forming a blue acid coordination compound (Figure 3c). The peaks at $152.7^{\circ} \mathrm{C}$ and $197.9^{\circ} \mathrm{C}\left(\Delta H=414.2 \mathrm{~J} \mathrm{~g}^{-1}\right)$ occur due to the loss of coordination water and formation of the $\mathrm{CoCl}_{2}$, observed in Figure $2 \mathrm{e}$ due to the blue-grayish color. ${ }^{11-13}$

In addition, the video exhibits dehydration of cobalt (II) chloride hexahydrate (supplementary material). Above $25^{\circ} \mathrm{C}$, the compound tends to turn blue, showing that on warmer days the rooster will also be this color. The shape of the crystal changes, which is likely due to complex formation (Figure 2). This behavior has been observed for other chloride compounds. ${ }^{15}$

$$
\begin{aligned}
& 3\left[\mathrm{CoCl}_{2}\left(\mathrm{OH}_{2}\right)_{4}\right] \cdot 2 \mathrm{H}_{2} \mathrm{O}_{(\mathrm{s})} \stackrel{\Delta T\left({ }^{\circ} \mathrm{C}\right)=31-202}{\stackrel{-18 \mathrm{H}_{2} \mathrm{O}_{(\mathrm{g})}}{\longrightarrow}} 3 \mathrm{CoCl}_{2(\mathrm{~s})}
\end{aligned}
$$

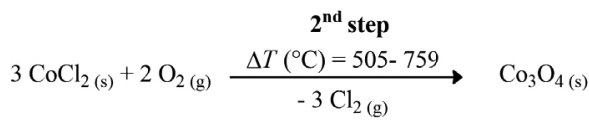

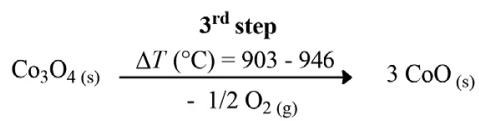

(a)

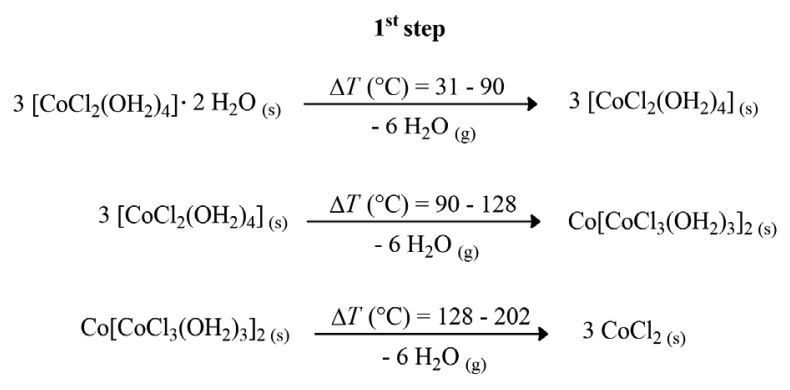

(b)

Figure 2. Thermal decomposition scheme proposed for the $\mathrm{CoCl}_{2} \cdot 6 \mathrm{H}_{2} \mathrm{O}$ in the (a) three steps and (b) detailed first step of mass loss 


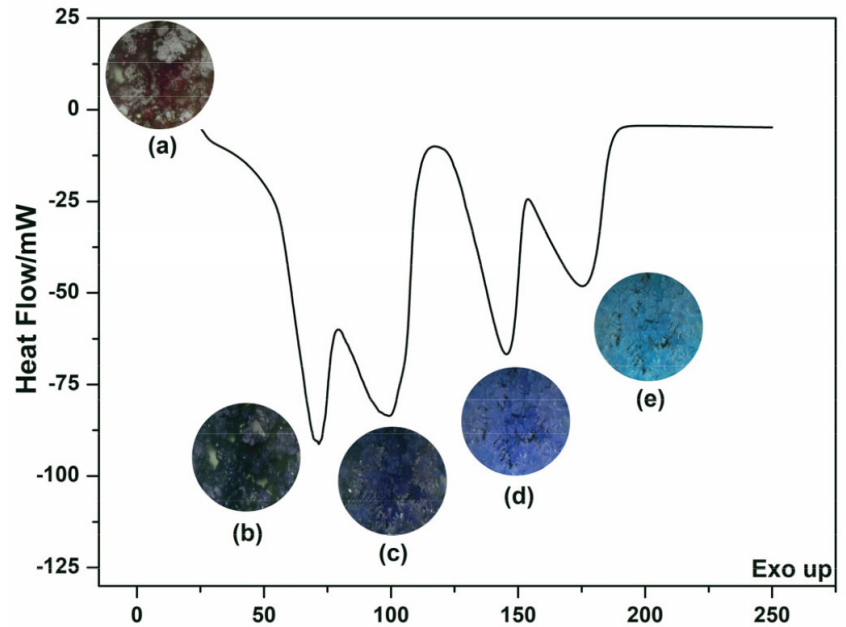

Figure 3. DSC curve for $\mathrm{CoCl}_{2} \cdot 6 \mathrm{H}_{2} \mathrm{O}$. Images are corresponding to the temperatures (a) 25.0, (b) 68.6, (c) 101.9, (d) 152.7 , (e) and $197.9^{\circ} \mathrm{C}$

In this sense, to understand how the rooster works, it is also necessary to understand what the relative humidity of the air is: the relationship between the amount of water in the air and the maximum that could exist at the same temperature. ${ }^{16}$ This means that if the temperature increases, the humidity varies inversely.

In addition, this study is related to other chemical concepts, such as chemical equilibrium. Le Châtelier's principle explains: if a system at equilibrium is disturbed by a change in temperature, pressure, or the concentration of one of the components, the system will shift its equilibrium position to counteract the effect of the disturbance. ${ }^{17}$

Thus, according to Le Châtelier's principle, the hydration/ dehydration processes in the $\mathrm{CoCl}_{2} \cdot 6 \mathrm{H}_{2} \mathrm{O}$ crystalline structure can be influenced over three ways: first, considering that dehydration is an endothermic process, an increase in the temperature of the environment will favor the loss of water molecules from the $\mathrm{CoCl}_{2} \cdot 6 \mathrm{H}_{2} \mathrm{O}$ crystalline structure. In this condition, the blue color prevails in the Portuguese good luck rooster. Second, assuming a high relative humidity (increase in the concentration of water molecules in the air) in the environment, the hydration process in the $\mathrm{CoCl}_{2} \cdot 6 \mathrm{H}_{2} \mathrm{O}$ crystalline structure will be favored. In this condition, the pink color prevails in the Portuguese good luck rooster. And third, the pressure reduction in the environment (due to the fact that the Portuguese Good Luck Rooster is above sea level) will favor the dehydration process of the $\mathrm{CoCl}_{2} \cdot 6 \mathrm{H}_{2} \mathrm{O}$ crystalline structure. In this condition, the blue color prevails in the Portuguese good luck rooster. Temperature, concentration, and pressure parameters influence the hydration/ dehydration process simultaneously, dynamically, and competitively.

Based on these, and thermoanalytical analysis performed, it was possible to determine the thermal behavior of $\mathrm{CoCl}_{2} \cdot 6 \mathrm{H}_{2} \mathrm{O}$ (main material of the Portuguese good luck rooster) when submitted to a quickly temperatures changing $\left(10{ }^{\circ} \mathrm{C} \mathrm{min}^{-1}\right)$. Demonstrating that when the environment is humid or has low temperature, the compound tends to turn pink (cobalt (II) chloride hexahydrate). On the other hand, when the climate is dry or in high temperature, the compound tends to turn blue.

\section{Microlearning}

Teaching is not transferring knowledge but creating the possibilities for its own production or construction. In this sense, this work sought not only to provide data, but to relate it to an experience, creating connections between the Portuguese good luck rooster, cobalt (II) chloride hexahydrate, thermal analysis, chemical equilibrium, microlearning methodology, and video production aiming at scientific dissemination on a YouTube channel (Explaining Chemistry), which is an open video platform. "Glycerol Thermal Analysis" video (link) provides a brief description of the main thermoanalytical techniques TG, DTA, and DSC, and the glycerol curve as an example, explaining how the curves are analyzed, since the TG-DTA and DSC curves are simple and easy to understand, serving as a basis for explaining the more complex thermal analysis of cobalt (II) chloride hexahydrate. Another video, "Is portuguese good luck rooster trustworthy?" (link), explains the TG/DTG-DTA and DSC curves of dehydration of hexahydrate cobalt chloride, which is present in the body of the rooster, to determine whether this adornment may reliably predict the weather.

\section{CONCLUSIONS}

Dehydration of cobalt (II) chloride hexahydrate was analyzed by thermoanalytical technics. TG/DTG-DTA curves shows that the compound is stable up to $31.2^{\circ} \mathrm{C}$ and the endothermic events of the DTA curve at $71.5^{\circ} \mathrm{C}, 120.3{ }^{\circ} \mathrm{C}, 158.7^{\circ} \mathrm{C}$, and $189.5^{\circ} \mathrm{C}$ are related to the loss of the six hydration water molecules $(\Delta m=45.2 \%)$, confirmed by stoichiometry. The first two events involve the formation of the complex $\left(\mathrm{Co}\left[\mathrm{CoCl}_{3}\left(\mathrm{OH}_{2}\right)_{3}\right]_{2}\right)$, and in the last, anhydrous $\mathrm{CoCl}_{2}$ is formed. The DSC curve confirms the events of the DTA curve, and the peak temperatures are close. Finally, microscopic analysis (video in the supplementary material) showed that above $25{ }^{\circ} \mathrm{C}$ the salt is no longer pink, and in the first endothermic event, the compound changes its shape due to the formation of a complex.

Therefore, thermal analysis determined that the Portuguese good luck rooster, which has cobalt (II) chloride hexahydrate in its body, is reliable to an immediate weather reading, because when the ambient humidity is high and the temperature is low, a pink color prevails, indicating a hydrated form. The increase of temperature decreases the concentration of water molecules in the air, favoring the loss of the hydration molecules of the hexahydrate salt and the blue color is predominant as consequence. Furthermore, it was possible to develop two videos that complement each other, following the methodology of microlearning, where an object that was part of the lives of many individuals can be related to thermoanalytical techniques, contributing to scientific dissemination.

\section{SUPPLEMENTARY MATERIAL}

Dehydration of cobalt (II) chloride hexahydrate video used in this work is available at http://quimicanova.sbq.org.br, AVI archive format, with open access. The video shows microanalysis of the dehydration of cobalt (II) chloride hexahydrate performed in the DSC analysis of this compound during heating between 25 and $250{ }^{\circ} \mathrm{C}$.

\section{ACKNOWLEDGMENTS}

The authors wish to thank CAPES (grants: 024/2012 Proequipment and 011/2009), São Paulo Research Foundation (FAPESP, grants: 2018/03460-6, and 2020/00906), and CNPq (grant: $301857 / 2018-0$ ) for financial support.

\section{REFERENCES}

1. Wajcman, J.; The British Journal of Sociology 2008, 59, 59.

2. Siswati, S.; Astiena, A. K; Savitri, Y.; J. Nonform. Educ. 2020, 6, 148.

3. Mishraa, L.; Guptab, T.; Shreeb A.; Int. J. Educ. Res. O. 2020, 1, 100012 .

4. Libâneo, J. C.; Pedagogia e pedagogos, para quê?, $8^{\text {th }}$ ed., Cortez: São Paulo, 2005, chap. 3. 
5. Giurgiu, L.; Sci. Bull. 2017, 22, 18.

6. Mohammed, G. S.; Wakil, K.; Nawroly, S. S.; Int. J. Educ. Res. Re. 2018, 3,32 .

7. Hug, T.; Didactics of Microlearning, Waxmann Verlag: Münster, 2007.

8. Sabri, T.; J. Educ. Teach. Learn. 2018, 2, 79.

9. Bissessar, C. S. G.; J. Educ. Pract. 2014, 5, 106.

10. Parussolo, A. P.; Lombarde, W.; Baron, A. M.; Experiências em Ensino de Ciências 2015, 10, 141.

11. Ribas, J.; Escuer, A.; Serra, M.; Vicente, R.; Thermochim. Acta 1986, $102,125$.

12. Duval, C.; Inorganic Thermogravimetric Analysis, $2^{\text {nd }}$ ed., Elsevier Publishing Company: New York, 1963, chap. 27.
13. Waizumi, K.; Masuda, H.; Ohtaki, H.; Tsukamoto, K.; Sunagawa, I.; Bull. Chem. Soc. Jpn. 1990, 63, 3426.

14. Mishra, S. K.; Kanungo, S. B.; J. Therm. Anal. 1992, 38, 2437.

15. Machado, R. G.; Gaglieri, C.; Alarcon, R. T.; Moura, A.; Almeida, A. C.; Caires, F. J.; Ionashiro, M.; Thermochim. Acta 2020, 689, 178615.

16. Callahan, C. W.; Elansari, A. M.; Fenton, D. L.; Postharvest Technology of Perishable Horticultural Commodities: Psychrometrics, Woodhead Publishing: Sawston, 2019.

17. Atkins, P.; Jones, L.; Laverman, L.; Chemical Principles: The Quest for Insight, $7^{\text {th }}$ ed., W. H. Freeman: New York, 2016. 